\title{
ANALISIS ENERGI PADA PERENCANAAN PEMBANGKIT LISTRIK TENAGA UAP (PLTU) DENGAN CYCLE TEMPO
}

\author{
MARLON HETHARIA \\ YOLANDA J. LEWERISSA
}

\author{
Jurusan Teknik Mesin \\ Program Study Diploma IV \\ Politeknik Katolik Saint Paul Sorong \\ Email:aln heth@yahoo.com; ruselloanz@yahoo.co.id
}

\begin{abstract}
ABSTRAK
Penelitian ini bertujuan untuk membuat pemodelan siklus uap (steam cycle) untuk Pembangkit Listrik Tenaga Uap (PLTU) dengan menggunakan program Cycle-Tempo dan untuk Mengetahui besarnya prestasi (energi) yang dihasilkan oleh siklus Uap (steam cycle) untuk Pembangkit Listrik Tenaga Uap (PLTU) pada berbagai kondisi dengan menggunakan program Cycle-Tempo.

Data yang diambil adalah data spesifikasi dan desain termal serta beberapa data pendukung yang berkaitan dengan bahan bakar dan perhitungan ekonomi dengan formulasi yang ada berdasarkan hukum pertama dan kedua termodinamika. perhitungan mengenai kesetimbangan energi pada sistem PLTU dapat digambarkan dengan diagram sankey (gambar 4.14), besar energi yang dihasilkan dari pembakaran batubara yakni $36088,89 \mathrm{~kW}$ sedangkan jumlah yang dapat diserap oleh fluida dalam boiler adalah 25262,22 kW. Kerugian energi pada boiler adalah sebesar 10826,67 kW atau sebesar 29,99\% merupakan kerugian energi yang terbawa melalui gas asap, adanya karbon yang tidak terbakar, kerugian energi akibat kelemba ban bahan bakar, terdapatnya hidrogen dalam bahan bakar, kerugian energi akibat radiasi dan konveksi serta kerugian energi yang terbawa melalui abu dan terak. Sedangkan energi yang diteruskan sebagai penggerak (input) komponen-komponen lain adalah sebesar 16651,96 kW namun dari sejumlah energi tersebut sebanyak 14993,25 kW dari energi yang keluar dari turbin masih dilepaskan melalui pendingin pada konsensor. Jumlah energi yang dapat ditransfer untuk menghasilkan energi listrik maksimum adalah 8351,95 kW atau sekitar 21,14\%. Dengan perhitungan berdasarkan hukum pertama termodinamika dimana daya yang dibangkitkan sebesar 8351,95 kW dan absorbsi energi pada boiler dari hasil pembakaran sebesar 36088,89 kW diperoleh efisiensi termal siklus sebesar 22,44\%.
\end{abstract}

Kata Kunci : Energi, PLTU, Efisiensi

\section{ABSTRACT}

This study attempts to make modeling steam (cycle of a steam cycle) for power plants steam power ( PLTU) using cycle-tempo program and to know the achievement ( energy) produced by the cycle of steam (of a steam cycle) for power plants steam power ( pltu) on various condition with on the cycle-tempo. The data were drawn is data specifications and thermal design and several the supporting data relating to fuel and economic calculations with formulations is under the law first and second thermodynamics. Calculation of equilibrium energy on pltu system can be described by diagram sankey, enormous energy is produced by the burning coal is 36088,89 $\mathrm{kw}$ while the number can be absorbed by a fluid in boiler is 25262,22 kw. Energy on a boiler loss noncompetitive purchase will be 10826,67 kw or equal to 29,99\% constituting a disadvantage energy is carried away through of smoke gas, the presence of carbon that were not burned, energy loss due to fuel moisture, existence of hydrogen in which the fuel, energy loss due to radiation and convection and the loss energy is carried away through the ashes in the slag. While energy that passes as the driving force of (input) other components noncompetitive purchase will be 16651,96 kw but from the amounts of energy 14993,25 kw than the energy out from turbine still is discharged through cooling on konsensor. The amount of energy can be transferred to produce electric energy maximum is $8351,95 \mathrm{kw}$ or about $21,14 \%$. With a rough estimate based on the first law of thermodynamics where power that is raised as much as $8351,95 \mathrm{kw}$ and either absorption energy on a boiler from its result as much as 36088,89 $\mathrm{kw}$ obtained thermal efficiency 22,44\% cycle as much as.

Keywords : energy, coal-fired power (PLTU), efficiency 


\section{PENDAHULUAN}

Pertumbuhan beban pada sistem kelistrikan wilayah Papua khususnya sistem kelistrikan mengalami peningkatan yang cukup besar, sehingga kebutuhan daya telah melampaui kemampuan pembangkit yang ada. Melihat kebutuhan tenaga listrik di Papua Barat khususnya di kota Sorong dan pada tahun 2016 telah sangat tinggi, sedangkan kemampuan PLN saat ini masih sangat terbatas. Pembangkit milik PLN yang ada hampir semua dalam kondisi yang kurang baik, ada beberapa yang sudah rusak, semua itu karena mesin sudah tua. Mengingat akan hal ini, maka PT PLN (Persero) sebagai perusahaan negara yang bertugas menyediakan kebutuhan listrik mencanangkan Program Percepatan Pembangunan Pembangkit Listrik.

Dengan adanya simulasi untuk perencanaan PLTU sekaligus memanfaatkan potensi batubara kalori rendah (low rank coal), dikarenakan batubara digunakan sebagai bahan bakar utama PLTU. Batubara adalah batuan sedimen yang dapat terbakar, terbentuk dari endapan organik utama yaitu sisa-sisa tumbuhan dan terbentuk melalui proses pembatubaraan. PLTU batubara memiliki beberapa keuntungan dibandingkan dengan pembangkit dengan bahan bakar lain, diantaranya adalah cadangan bahan bakar batubara tersedia cukup besar dan melimpah di Indonesia, khususnya yang berkalori rendah. Dengan menggunakan batubara berkalori rendah yang kurang diminati untuk diekspor, penambangan batubara sebagai hasil galian lokal akan semakin meningkat.

Pembangkit Listrik Tenaga Uap adalah pembangkit yang mengandalkan energi kinetik dari uap untuk menghasilkan energi listrik. Bentuk utama pembangkit listrik jenis ini adalah Generator yang di hubungkan ke turbin dimana untuk memutar turbin diperlukan energi kinetik dari uap panas atau kering. Dalam PLTU, energi primer yang dikonversikan menjadi energi listrik adalah bahan bakar. Bahan bakar yang digunakan dapat berupa batubara (padat), minyak (cair), atau gas. Ada kalanya PLTU menggunakan kombinasi beberapa macam bahan bakar. Konversi energi tingkat pertama yang berlangsung dalam PLTU adalah konversi energi primer menjadi energi panas (kalor). Hal ini dilakukan dalam ruang bakar dari ketel uap PLTU. Energi panas ini kemudian dipindahkan ke dalam air yang ada dalam pipa ketel untuk menghasilkan uap yang dikumpulkan dalam drum dari ketel. Uap dari drum ketel dialirkan ke turbin uap. Dalam turbin uap, energi uap dikonversikan menjadi energy mekanis penggerak generator, dan akhirnya energi mekanik dari turbin uap ini dikonversikan menjadi energi listrik oleh generator.

Analisis dan perancangan sistem siklus uap (Steam Cycle) untuk PLTU dilakukan dengan pemodelan proses termodinamika siklus sistem dengan metode volume kendali tetap (fixed control volume method) melalui penggunaan kode komputer Cycle Tempo. Cycle Tempo adalah program untuk pemodelan termodinamika dan optimalisasi sistem untuk produksi listrik, panas dan pendinginan. Sistem tersebut terdiri dari beberapa komponen yang saling berhubungan dengan pipa sehingga membentuk hubungan antara massa dan energi. Tujuan utama dari Cycle Tempo adalah untuk menghitung ukuran massa yang relevan dan aliran energi dalam sistem. Jumlah jenis komponen dan cara penyusunan sehingga saling berhubungan berbeda dari kasus ke kasus, oleh karena itu sistem harus diatur susunan komponen sesuai dengan kebutuhan. Program ini berisi sejumlah besar model untuk komponen dan pipa yang mana kita dapat membuat model sistem sesuai yang diinginkan.

Perangkat lunak ini sangat ideal untuk perancangan konseptual dari suatu sistem pembangkit daya (power plant). Cycle Tempo dapat digunakan untuk memodelkan sistem kogenerasi dengan baik. Dalam perjalanan pengembangan dan penyempurnaan, perangkat lunak ini telah digunakan dan divalidasi untuk optimasi sistem energi. Oleh karena itu Cycle Tempo cukup memadai untuk digunakan dalam pengembangan dan optimasi desain konseptual PLTU.

Dengan dasar pemikiran dan pandangan diatas maka penulis bermasksud melakukan penelitian pada sistem pembangkit listrik tenaga uap (PLTU) guna menganalisis baik secara energi dengan menggunakan program Cycle Tempo.

\section{KAJIAN PUSTAKA \\ Konsep Dasar Termodinamika \\ Hukum pertama termodinamika menyatakan bahwa energi tidak dapat diciptakan atau dimusnahkan, tetapi dapat diubah dari satu bentuk ke bentuk yang lain. Hukum ini memperkenalkan konsep energi dalam dan menghasilkan prinsip kekekalan energi atau juga dikenal dengan istilah konservasi energi. Untuk}


sebuah volume kontrol, hukum pertama dapat ditulis sebagai:

$$
\begin{aligned}
& \underset{d(U+K E+P E)}{Q C V+\sum_{2} \dot{m}} i\left[h_{i} V_{i} 2+g z_{i} \sim\right. \\
& d t \quad+ \\
& \sum \dot{m}_{e}\left[h_{e}+V_{e 2} 2+g z_{e} l+W C V \ldots\right. \text { (1) }
\end{aligned}
$$

Kelemahan pada pendekatan hukum pertama Termodinamika adalah bahwa hukum ini tidak memperhitungkan terj adinya penurunan kualitas energi.

Untuk itu, pendekatan hukum kedua Termodinamika telah memberikan konsep efisiensi yang lebih baik. Dalam hukum kedua Termodinamika atau dikenal $\mathrm{j}$ uga sebagai hukum degradasi energi dikemukakan bahwa tidak ada proses pengubahan energi yang efisien sehingga pastilah akan terjadi penurunan kualitas energi didalamnya. Kualitas energi ini disebut sebagai eksergi. Eksergi ini dapat ditransfer di antara sistem dan dapat dihancurkan oleh irreversibiltas di dalam sistem. dalam pendekatan hukum kedua termodinamika ini strategi efisiensi energi yang direkomendasikan adalah pemanfaatan energi secara optimal termasuk di dalamnya pemanfaatan eksergi-eksergi, sehingga dalam pendekatan i ni diharapkan tidak ada energi dan eksergi yang terbuang percuma ke lingkungan. $\mathrm{H}$ ukum kedua termodi namika memperlihatkan arah perubahan alami distribusi energi dan memperkenalkan prinsip peningkatan entropi. Konsep entropi menj elaskan secara kuantitatif kerugian energi daya guna dalam seluruh transformasi yang terjadi secara alami.

\section{Hukum Pertama dan Kedua Termodinamika}

Hukum pertama termodinamika memperkenalkan konsep energi dalam dan menghasilkan prinsip kekekalan energi. Hukum ini menegaskan keekuivalenan perpindahan kerj a dan kalor sebagai bentuk i nteraksi yang memungkinkan. Hukum pertama dapat dinyatakan secara sederhana; selama interaksi antara sistem dan lingkungan, jumlah energi yang diperoleh sistem harus sama dengan energi yang dilepaskan oleh lingkungan. Energi dapat melintasi batas dari suatu sistem tertutup dalam dua bentuk yang berbeda : panas (heat) dan kerj a (work).

Panas (heat) dideinisikan sebagai bentuk energi yang dapat berpindah antara dua sistem (atau dari sistem ke lingkungan) dengan sifat perbedaan temperatur. Panas adalah sebuah energi dalam keadaan transisi, dia dikenali jika hanya melewati batas sistem sehingga dalam termodinamika panas sering diistilahkan dengan transfer panas (heat transfer). Suatu proses jika tidak terjadi perpindahan panas disebut proses adiabatis. Ada dua cara suatu proses dapat dikatakan adiabatis; pertama, sistem diisolasi sempurna sehi ngga tidak ada energi panas yang keluar, kedua, antara sistem dan lingkungan berada pada temperatur yang sama sehingga tidak terjadi aliran panas karena perbedaan temperatur. Dari pengertian di atas, tidak harus disamakan pengertian proses adiabatis dengan proses isotermal. Satuan energi panas adalah Joule, kJ (atau Btu). Konvensi tanda yang digunakan untuk panas adalah:

$\mathrm{Q}>0$ : panas dipindahkan ke sistem

$\mathrm{Q}<0$ : panas dipindahkan dari sistem

Kerja (work) dilakukan oleh suatu sistem pada lingkungannya jika memberikan pengaruh utama pada segala sesuatu yang berada di luar sistem berupa peningkatan suatu beban. Peningkatan suatu beban pada dasarnya berupa gaya yang bekerja pada suatu jarak tertentu, sehingga konsep kerja menurut termodinamika merupakan suatu perluasan alamiah dari konsep kerja dalam mekanika. Pengujian mengenai apakah suatu interaksi telah terjadi, tidak selalu berarti bahwa telah terjadi peningkatan berat aktual, atau bahwa gaya secara nyata telah bekerja pada suatu jarak tertentu, tetapi bahwa pengaruh utama dapat berupa peni ngkatan ketinggian suatu beban. Kerja W dinotasikan dengan nilai:

$$
\begin{aligned}
& \mathrm{W}>0 \text { : kerja dilakukan oleh sistem } \\
& \mathrm{W}<0 \text { :kerja dilakukan pada sistem }
\end{aligned}
$$

Keja merupakan suatu cara untuk memindahkan energi. Jadi pengertian kerja tidak meruj uk pada apa yang sedang dipindahkan dari satu sistem ke sistem yang lain, atau apa yang sedang disimpan ke dalam sistem. Energi dipindahkan dan disimpan ketika kerja dilakukan.

Energi Dalam termodinamika teknik, energi dari sebuah sistem terdiri dari tiga kontribusi makroskopik: energi kinetik (EK), energi dalam (U), dan energi potensial (EP). Perubahan energi antara dua keadaan dalam hal kerja pada sebuah proses adiabatik adalah :

$$
\begin{aligned}
& E_{2} 2 \sim E_{1}=\sim W a d \\
& (2)
\end{aligned}
$$

Dengan W_ad adalah kerja netto untuk suatu proses adiabatik diantara dua keadaan. Symbol E menunjukan energi total sistem. Energi total meliputi energi kinetik, energi potensial dan bentuk energi lainnya. Bentuk perubahan energi lainnya disatukan sebagai 
energi dalam sistem, dan energi dalam merupakan sifat eksentif sistem karena merupakan energi total. Maka persamaannya menjadi :

$E_{2}-E_{1}=\left(E K_{2}-E K_{1}\right)+\left(E P_{2}-E P_{1}\right)+\left(U_{2}-U_{1}\right)$ $\left(E_{2} K_{2}-E K_{1}\right)+\left(E_{2}-E P_{1}\right)+\left(U_{2}-U_{1}\right)=-W_{a d}$ (3)

Aspek mendasar dari konsep energi adalah kekekalan energi. Dengan demikian, agar sistem mengalami perubahan energi yang sama besar selama proses non-adiabatik maupun adiabatik, maka jumlah netto energi yang dipindahkan ke sistem untuk setiap proses di atas harus sama besar. Tampak bahwa interaksi kalor merupakan bentuk perpindahan energi. Jumlah energi Q yang dipindahkan ke sistem tertutup dengan cara lain selain kerja harus sama dengan jumlah perubahan energi sistem dan jumlah energi yang dipindahkan dari sistem dalam bentuk kerj a. Sehingga :

$Q=\left(E_{2}-E_{1}\right)+W$

$E_{2}-E_{1}=Q-W \ldots \ldots \ldots . . . .$.

Persamaan ini menyatakan bahwa perubahan energi sistem sama dengan perpindahan energi netto ke dalam sistem.

Hampir semua sistem tertutup yang ditemui dalam praktek adalah sistem stationer, yang umumnya tidak melibatkan perubahan kecepatan dan ketinggian selama proses. Untuk sistem tertutup yang stasioner perubahan energi kinetik dan energi potensial dapat diabaikan.

Hukum kedua termodinamika memperlihatkan arah perubahan alami distibusi energi dan memperkenalkan prinsip peni ngkatan entropi. Konsep entropi menjelaskan secara kuantitatif kerugian energi yang berdayaguna dalam seluruh transformasi yang terjadi secara alami.

\section{Entropi}

Suatu besaran adalah sebuah sifat jika, dan hanya jika perubahan nilai yang terj adi di antara dua keadaan tidak bergantung pada proses. Entropi merupakan sebuah sifat, maka perubahan entropi sebuah sistem yang berlangsung dari keadaan satu ke keadaan lain, mempunyai nilai yang sama untuk semua proses, baik proses reversibel maupun proses ireversibel. Entropi dapat didefenisikan sebagai persamaan integrasi tertentu tanpa disertai dengan pengertian fisik tertentu

$$
\begin{aligned}
\Delta S=S_{2}-S_{1}=\int_{R}(\delta Q \\
T) i n t \text { rev }
\end{aligned}
$$

Persamaan di atas dapat digunakan untuk menentukan perubahan entropi, dan setelah dikaji lebih lanjut, nilai ini menunjukan besar perubahan entropi sistem untuk semua proses diantara dua keadaan.

Perubahan entropi suatu sistem tertutup selama proses ireversibel selalu lebih besar daripada transfer entropi, yaitu beberapa entropi yang dihasilkan atau dibuat selama proses ireversibel. dan generasi ini sepenuhnya disebabkan adanya irreversibilities. Entropi yang dihasilkan selama proses ini disebut entropi generasi dan dilambangkan oleh Sgen. Memperhatikan bahwa perbedaan antara perubahan entropi suatu sistem tertutup dan transfer entropi sama dengan generasi entropi, persamaan (5) dapat ditulis dalam bentuk kesetaraan sebagai:

$\Delta S_{s y s}=\Delta S 2-S_{1} \overline{\overline{2}}_{T} \int_{T} \delta Q$

Sistem dan sekitarnya dapat dilihat sebagai dua subsistem dari sebuah sistem yang terisolasi, dan perubahan entropi dari sistem yang terisolasi ini selama proses adalah jumlah dari perubahan entropi dari sistem dan sekitarnya, yang sama dengan generasi entropi jika sistem yang terisoiasi tidak melibatkan transfer entropi.

$S_{\text {gen }}=\Delta S_{\text {total }}=\Delta S_{\text {sys }}+\Delta S_{\text {surr }} \geq 0$ (7)

\section{Perangkat Lunak Cycle Tempo \\ Perangkat lunak cycle tempo} (Thermodynamics Energy Sistem And Mass Flow Calculation For Power) dikembangkan oleh Departement of Thermal Power Engineering dari Delfi University of Technology dengan TNO Institute of Envoironmental Sciences. Perangkat lunak cycle tempo pada awal nya dikembangkan untuk memodelkan Thermal Power Plant. Perangkat lunak cycle tempo merupakan program yang digunakan untuk pemodelan termodinamika dan optimalisasi sistem konversi energi seperti pembangkit dan sistem refigerasi. Tujuan utama dari cycle tempo adalah menghitung ukuran aliran massa dan energi dalam sistem, termasuk didalamnya yaitu sifatsifat termodinamika, komposisi gas, laju aliran massa. Perangkat lunak cycle tempo berisi sejumlah besaran model-model komponen dan pipa yang dengan keduanya kita bisa membuat model sistem yang kita inginkan. Program ini mempunyai graphical user interface yang moderen yang memudahkan pengguna, mengoperasikannya serta dapat melihat hasil perhitungan berdasarkan variabel yang relevan dalam berbagai variasi tabel dan grafik seperti 
Jurnal Voering Vol. 3 No. 1 Juli 2018

system efficiencies, energy balance of the 
system, energy dan energy flows, quantities of heat transferred, temperature profiles in heat exchanger, h-s diagram of cycle.

\section{METODOLOGI PENELITIAN}

Penelitian dilakukan dengan data-data teknis (variable desain) berupa data kesetimbangan eksergi serta data-data untuk kepentingan analisis. Kemudian Membuat pemodelan siklus uap (steam cycle) untuk Pembangkit Listrik Tenaga Uap (PLTU) dengan menggunakan program Cycle-Tempo untuk dapat mengetahui besarnya prestasi (energi) yang dihasilkan oleh siklus Uap (steam cycle) untuk Pembangkit Listrik Tenaga Uap (PLTU) pada berbagai kondisi dengan menggunakan program CycleTempo. Perhitungan laju kesetimbangan energi pada sistem Pembangkit Listrik Tenaga Uap (PLTU).

\section{PEMBAHASAN}

Dari Gambar 1 memperlihatkan data-data awal/data termodinamika dan juga data bahan bakar dimana PLTU menggunakan bahan bakar batubara kalori rendah dengan nilai $\mathrm{LHV}=$ $20047,43 \mathrm{~kJ} / \mathrm{kg}$.
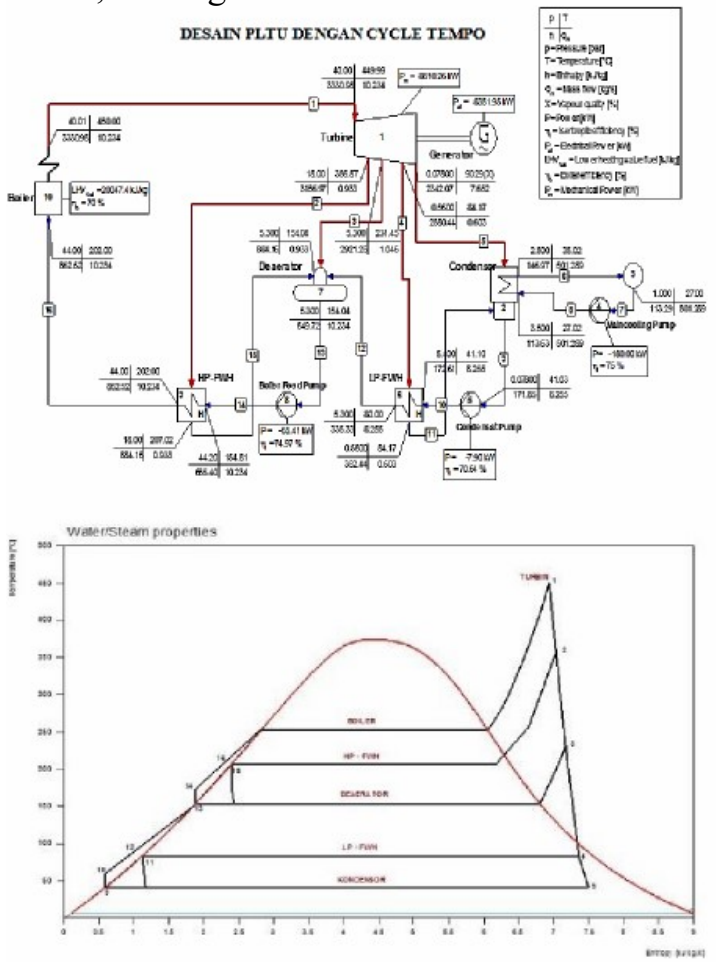

Gambar 1. Skema PLTU dan Diagram T-s

Hasil pengolahan data pada penelitian maka dapat dilihat bahwa :

\section{Kesetimbangan Energi}

Berdasarkan hasil perhitungan maka diperoleh kesetimbangan energi pada setiap kondisi aliran (keadaan). Adapun berdasarkan hukum pertama termodinamika, energi pada setiap konsisi aliran (keadaan) dapat dilihat padaTabel 1.

Tabel 1. Kesetimbangan energi pada setiap kondisi aliran

\begin{tabular}{|c|c|c|c|c|c|}
\hline $\begin{array}{l}\text { No } \\
\text { Pipa }\end{array}$ & ${ }_{m i}(\mathbf{k g} / \mathbf{s})$ & $\stackrel{P}{\text { (bar) }}$ & $\begin{array}{c}\mathrm{T} \\
\left({ }^{\circ} \mathrm{C}\right)\end{array}$ & $\underset{(\mathbf{k} / \mathrm{kg})}{h}$ & $\underset{(\mathrm{MW})}{\mathrm{E}}$ \\
\hline \multirow[t]{2}{*}{1} & \multirow[t]{2}{*}{10,234} & 40,011 & 450,00 & \multirow[t]{2}{*}{3330,98} & \multirow[t]{2}{*}{34,0892} \\
\hline & & 40,000 & 449,99 & & \\
\hline 2 & 0,93342 & 18,000 & 356,87 & 3156,97 & 2,9468 \\
\hline 3 & 1,0461 & 5,299 & 231,45 & 2921,25 & 3,0559 \\
\hline 4 & 0,60288 & 0,560 & 84,17 & 2580,44 & 1,5557 \\
\hline 5 & 7,6516 & 0,078 & 41,03 & 2342,07 & 17,9206 \\
\hline 6 & 501,29 & 2,500 & 35,02 & 146,97 & 73,6746 \\
\hline 7 & 501,29 & 1,000 & 27,00 & 113,29 & 56,7911 \\
\hline 8 & 501,29 & 3,500 & 27,02 & 113,63 & 56,9616 \\
\hline 9 & 8,2545 & 0,078 & 41,03 & 171,85 & 1,4185 \\
\hline 10 & 8,2545 & 5,400 & 41,10 & 172,61 & 1,4248 \\
\hline \multirow[t]{2}{*}{11} & \multirow[t]{2}{*}{0,60288} & 0,560 & 84,17 & \multirow[t]{2}{*}{352,44} & \multirow[t]{2}{*}{0,2125} \\
\hline & & 0,078 & 41,03 & & \\
\hline 12 & 8,2545 & 5,300 & 80,00 & 335,33 & 2,7680 \\
\hline 13 & 10,234 & 5,299 & 154,04 & 649,72 & 6,6492 \\
\hline 14 & 10,234 & 44,200 & 154,81 & 655,4 & 6,7074 \\
\hline \multirow[t]{2}{*}{15} & \multirow[t]{2}{*}{0,93342} & 18,000 & 207,02 & \multirow[t]{2}{*}{884,16} & \multirow[t]{2}{*}{0,8253} \\
\hline & & 5,300 & 154,04 & & \\
\hline 16 & 10,234 & 44,000 & 202,00 & 862,52 & 8,8270 \\
\hline
\end{tabular}

Gambar 2 memperlihatkan hasil perhitungan kesetimbangan energi untuk setiap komponen PLTU.

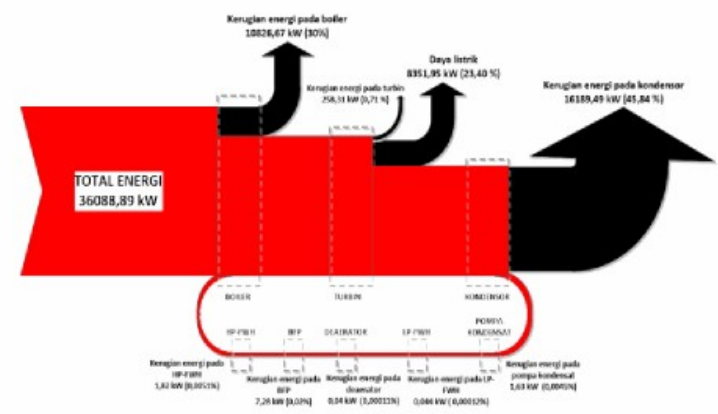

Gambar 2. Diagram Sankey kesetimbangan energi

Penelitian ini menunjukan mengenai kesetimbangan energi pada sistem PLTU dimana 
besar energi yang dihasilkan dari pembakaran batubara yakni $36088,89 \mathrm{~kW}$ dengan laju aliran massa bahan bakar sebesar $1,8002 \mathrm{~kg} / \mathrm{s}$, diperoleh efisiensi termal siklus sebesar 22,44\%. Sedangkan jumlah yang dapat diserap oleh fluida dalam boiler adalah 25262,22 kW. Kerugian energi pada boiler adalah sebesar 10826,67 kW atau sebesar $29,99 \%$. kerugian energi pada boiler disebabkan karena adanya kerugian energi yang terbawa melalui gas asap, adanya karbon yang tidak terbakar, kerugian energi aki bat kelembaban bahan bakar, terdapatnya hidrogen dalam bahan bakar, kerugian energi akibat radiasi dan konveksi serta kerugian energi yang terbawa melalui abu dan terak. Dalam perhitungan dapat disimpulkan bahwa kerugian energi yang terbesar adalah pada kondensor sebesar $45,84 \%$.

Hasil perhitungan serupa juga dinyatakan pada beberapa referensi yaitu (Ganapathy dkk.,2009) dalam analisis energi pada PLTU $50 \mathrm{MW}$ di India, menyatakan bahwa kerugian energi terbesar adalah pada kondensor yaitu sebesar 39\%, (Rashad dkk., 2009) dalam analisis energi pada PLTU 1260 MW di Mesir, menyatakan bahwa kerugian energi terbesar adalah pada kondensor dengan beban penuh sebesar $56,4 \%$, beban $75 \%$ sebesar $55,2 \%$ dan beban 50\% sebesar 54,4\% dan (Vosough, 2012) dalam analisis energi pada PLTU menyatakan bahwa kerugian energi terbesar adalah pada kondensor yaitu sebesar 50\%.

Berdasarkan hasil perhitungan maka diperoleh :

Tabel 2. Perhitungan energi masuk dan keluar ada pembangkit

\begin{tabular}{|clll|}
\hline & Komponen & $\begin{array}{l}\text { Energi } \\
(\mathrm{kW})\end{array}$ & $\begin{array}{l}\text { Total Energi } \\
(\mathrm{kW})\end{array}$ \\
\hline Energi input & Boiler & 36089,05 & \\
\hline & & & 36089,05 \\
\hline Daya generator & Generator & 8351,95 & \\
\hline & & & 8351,95 \\
\hline Daya yang & Maincooling Pump & 180,00 & \\
digunakan & Condensat Pump & 7,90 & \\
& Boiler Feed Pump & 65,41 & \\
\hline & & & 253,32 \\
\hline Daya output & & 7367,32 \\
\hline
\end{tabular}

\footnotetext{
Maka,

Gross Thermal Efficiency

Total Produced ElectriclMechanical

Power Net Thermal Efficiency

Total Energy Input

Gross Thermal $\frac{8351,95}{36089,05}$

$=0,23142615=23,14 \%$
}

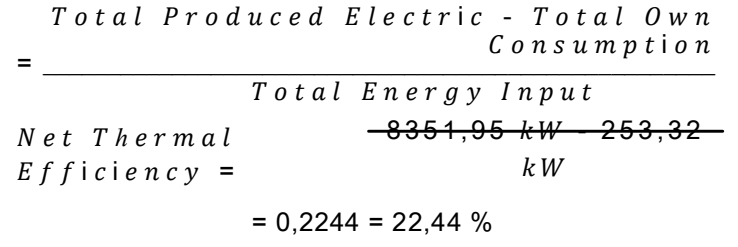

Berdasarkan data-data parameter ke dalam program cycle tempo maka diperoleh hasil berupa tekanan $(\mathrm{P})$, temperatur $(\mathrm{T})$, entalpi (h), entropi (s), laju aliran massa $\left(\phi \_m\right)$ dan kualitas uap (x). Dengan data tersebut maka dilakukan perhitungan termodi namika berupa energi fluida pada setiap kondisi aliran pada sistem (tabel 1) pada setiap kondisi aliran .

Berdasarkan perhitungan mengenai kesetimbangan energi pada sistem PLTU dapat digambarkan dengan diagram sankey (gambar 2), besar energi yang dihasilkan dari pembakaran batubara yakni 36088,89 kW sedangkan jumlah yang dapat diserap oleh fluida dalam boiler adalah $25262,22 \mathrm{~kW}$.

Kerugian energi pada boiler adalah sebesar 10826,67 $\mathrm{kW}$ atau sebesar 29,99\% merupakan kerugian energi yang terbawa melalui gas asap, adanya karbon yang tidak terbakar, kerugian energi akibat kelembaban bahan bakar, terdapatnya hidrogen dalam bahan bakar, kerugian energi akibat radiasi dan konveksi serta kerugian energi yang terbawa melalui abu dan terak. Sedangkan energi yang diteruskan sebagai penggerak (input) komponen-komponen lain adalah sebesar $16651,96 \mathrm{~kW}$ namun dari sejumlah energi tersebut sebanyak 14993,25 kW dari energi yang keluar dari turbin masih dilepaskan melalui pendingin pada konsensor. Dalam perhitungan dapat disimpulkan bahwa kerugian energi yang terbesar adalah pada kondensor, Hasil perhitungan serupa juga dinyatakan pada beberapa referensi $[8,16,28]$. Jumlah energi yang dapat ditransfer untuk menghasilkan energi listrik maksimum adalah $8351,95 \mathrm{~kW}$ atau sekitar 21,14\%. Dengan perhitungan berdasarkan hukum pertama termodinamika dimana daya yang dibangkitkan sebesar 8351,95 kW dan absorbsi energi pada boiler dari hasil pembakaran sebesar 36088,89 $\mathrm{kW}$ diperoleh efisiensi termal siklus sebesar $22,44 \%$.

\section{PENUTUP}

Kesimpulan

Dari hasil perhitungan dan pembahasan dapat ditarik kesimpulan sebagai berikut:

1. Setelah menganalisa kesetimbangan energi dan eksegi, dapat diketahui bahwa kerugian 
energi terbesar yaitu pada kondensor sebesar 41,54\% sedangkan kerugian eksergi (eksergi destruksi) terbesar pada boiler sebesar $56,83 \%$.

2. Total modal investasi (TCI) pembangunan dan operasional PLTU Merauke sebesar $\$ 33.802 .140$. Dengan suku bunga $10 \%$ dengan laju inflasi $5 \%$ serta serta biaya bahan bakar sebesar \$ 0,2/GJ-LHV diperoleh biaya satuan listrik yang disamakan (MPUC) sebesar $\$ 0,0899 / \mathrm{kWh}$ atau Cent $\$ 8,99 / \mathrm{kWh}$. Sedangkan laju biaya produksi total (C $\mathrm{C}^{*}$ (p tot)) sebesar $\$ 1694,03 / \mathrm{h}$.

3. Setelah menganalisis dan mengevaluasi termoekonomi maka komponen-komponen utama yang perlu mendapat perhatian dalam evaluasi termoekonomi adalah boiler dengan laj u biaya investasi dan laj u biaya eksergi destruksi sebesar $\$ 786,59 /$ h dan faktor eksergoekonomi sebesar 73,38\%. Komponen kedua yang perlu mendapat perhatian adalah turbin, dengan laju biaya investasi dan eksergi destruksi $\$ 499,87 / \mathrm{h}$ dan faktor eksergoekonomi yang cukup tinggi yaitu sebesar $90,82 \%$. Sedangkan komponen ketiga yang $\mathrm{j}$ uga perlu mendapat perhatian adalah kondensor dengan laju biaya investasi dan eksergi destruksi \$ $167,23 / \mathrm{h}$ dan faktor eksergoekonomi sebesar $49,38 \%$.

\section{DAFTAR PUSTAKA}

[1]. Amirabedin E., and D. Mcllveen Wright. (2013). A Feasibility of Co-Firing Biomass In The Thermal Power Plant at Soma in Order to Reduce Emission: an Exergy Approach. Int. J. Eviron Res, :(139-154).

[2]. Amirabedin E., \& M. Zeki Yilmazoglu. (2011). Design and Exergy Analysis of a Thermal Power Plant Using Different Types of Turkish Lignite. International Journal of Thermodynamics (IJoT) Vol. 14 (No. 3):(125-133).

[3]. Bejan A., Tsatsaronis G. \& Moran M. (1996). Thermal Design and Optimization. New York: A Wiley-Interscience Publication.

[4]. Ganapathy T., Alagumurthi N., Gakkhar R. P. \& Murugesan K. (2009). Exergy Analysis of Operating Lignite Fired Thermal Power Plant. Journal of
Engineering Science and Technology Review, 2 (1):(123-130).

[5]. Kaushik S. C., Reddy V. Siva \& Tyagi S. K. (2011). Energy and exergy analyses of thermal power plants: Areview. Elsevier, Renewable and Sustainable Energy Reviews 15: (1857-1872).

[6]. Li Yong \& Liu Lei. (2012). Exergy Analysis of 300MW Coal-Fired Power Plant. Elsevier, Energy Procedia 1 7:(926 932).

[7]. Modesto M., \& S. A. Nebra. (2009). Exergoeconomic analysis of the power generation system using blast furnace and coke oven gas in a Brazilian steel mill. Elsevier, Applied Thermal Engineering 29:(21 27-2136).

[8]. Nag, P K. Power Plant Engineering. (2002). New York: McGraw-Hill International.

[9]. Rashad A., \& Maihy A. El. Energy and Exergy Analysis of a Steam Power Plant in Egypt. International Conference on Aerospace Sciences \& Aviation Technology, May 26-28:(1-12).

[10]. Saidur R., Ahamed J. U. \& Masjuki H. H. (2010). Energy, exergy and economic analysis of industrial boilers. Elsevier, Energy Policy 38:(2188-2197).

[11]. Vosough Amir. (2012). Improving Steam Power Plant Efficiency Through Exergy Analysis: Ambient Temperature. International Conference on Mechanical, Production and Automobile Engineering (ICMPAE), Singapore April 28-29:(209212).

[12]. Xiong J., Zhao H., Zhang C., Zheng C \& Luh P. B. (2012). Thermoeconomic operation optimization of a coal-fired power plant. Elsevier, Energy 42:(486496). 